\title{
TRABALHO, SOFRIMENTO E ADOECIMENTO: A REALIDADE DE AGENTES COMUNITÁRIOS DE SAÚDE NO SUL DO BRASIL
}

\author{
WORK, SUFFERING AND ILLNESS: THE REALITY OF COMMUNITY \\ HEALTH AGENTS IN SOUTHERN BRAZIL
}

TRABAJO, SUFRIMIENTO Y PADECIMIENTO: LA REALIDAD DE AGENTES

COMUNITARIOS DE SALUD EN EL SUR DE BRASIL

\author{
Suzane Beatriz Frantz Krug ${ }^{1}$ \\ Camila Dubow ${ }^{2}$ \\ Amanda Corrêa dos Santos ${ }^{3}$ \\ Bruno Dittberner Dutra ${ }^{4}$ \\ Leni Dias Weigelt ${ }^{5}$ \\ Luciane Maria Schmidt Alves ${ }^{6}$
}

Resumo $\mathrm{O}$ estudo que deu origem a este artigo teve por objetivo analisar como o agente comunitário de saúde avalia seu contexto de trabalho e os possíveis fatores que contribuem para seu sofrimento/adoecimento. Tratou-se de um estudo transversal, descritivo, de abordagem quantitativo-qualitativa, com agentes de saúde de 13 municípios da região central do estado do Rio Grande do Sul, no ano de 2014. Utilizaram-se para a coleta de dados um questionário sociodemográfico, o 'Inventário de trabalho e risco de adoecimento' e entrevista. Os dados foram examinados por meio da análise de conteúdo. As situações de sofrimento relacionaram-se ao não reconhecimento profissional, ritmos excessivos, sobrecarga de trabalho, conflitos com a comunidade, não resolutividade das ações, indisponibilidade de materiais e insumos somados à localização geográfica da unidade de saúde e das residências dos usuários, tipo de estratégia e gestão da saúde. Concluiu-se que o contexto de trabalho do agente de saúde pode resultar em sofrimento/adoecimento desses trabalhadores.

Palavras-chave agentes comunitários de saúde; trabalho; doença.

\begin{abstract}
The aim of this study was to analyze how community health agents evaluate the work context and possible factors that contribute to their suffering/illness. This was a cross-sectional, descriptive, quantitative-qualitative study carried out with health agents from 13 municipalities in the central region of the state of Rio Grande do Sul, Brazil, in 2014. The 'Work and Risk of Illness Inventory' sociodemographic questionnaire and interview were used to collect data. The data were analyzed through content analysis. The situations of suffering were related to the lack of professional recognition, an excessive pace, work overload, conflicts with the community, lack of resolution of actions, unavailability of materials and inputs, in addition to the geographic location of the health unit and of the users' homes, type of health strategy, and management. It was concluded that the health agent's working environment can cause suffering/illness among these workers.
\end{abstract}

Keywords community health agents; work; illness. 


\section{Introdução}

Com o Programa de Agentes Comunitários de Saúde (Pacs), existente no Brasil desde 1990, iniciou-se o trabalho mais próximo às comunidades. A lei n. 10.507, de 2002, criou a profissão de agente comunitário de saúde (ACS), tendo como principal requisito a residência do profissional na comunidade na qual atua (Brasil, 2002).

Sobre o contexto de trabalho do ACS, a legislação brasileira regulamenta que essa profissão é exercida exclusivamente no âmbito do Sistema Único de Saúde (SUS), por meio de ações de prevenções de doença e promoção da saúde. Nesse sentido, o agente aparece como um profissional integrante da Estratégia Saúde da Família (ESF), tornando-se importante elo de comunicação e vínculo entre comunidade e serviço de saúde, uma vez que conhece a dinâmica social daquela população (Menegussi, Ogata e Rosalini, 2014; Brasil, 2012). A população percebe o ACS como capaz de trazer respostas quanto à resolutividade de suas demandas, facilitando o acesso dela aos serviços de saúde (Menegussi, Ogata e Rosalini, 2014; Pinheiro e Guanaes-Lorenzi, 2014).

Outro fator relevante na dinâmica de trabalho do ACS é o compromisso na busca por melhores condições de vida e de saúde da população, no sentido social e solidário, uma vez que seu local de trabalho é o mesmo lugar no qual reside, estando presente forte desejo por mudanças e, ao mesmo tempo, sentimentos de frustração perante as demandas não resolutivas (Menegussi, Ogata e Rosalini, 2014; Lopes et al., 2012).

Sabe-se que tanto o ambiente do trabalho quanto a organização do processo de trabalho são possíveis causadores de sofrimento profissional. No caso do ACS, destaca-se que a mediação realizada por ele entre comunidade e equipe de saúde pode representar um potente estressor em decorrência da pressão exercida por esses dois universos no desempenho de seu trabalho, em que são depositados grandes anseios e expectativas. Sobre isso, ainda está muito associada, na visão da comunidade, a impossibilidade de desvincular as atividades de trabalho de sua vida privada (Santos, Vargas e Reis, 2014; Justo, Gomes e Silveira, 2015).

Salienta-se que o ACS apresenta um processo de trabalho complexo. É necessário compreendê-lo como uma atividade que tem um caráter singular, pois na ação de trabalhar são convocados saberes elaborados pelo sujeito em toda a sua história, os quais entram em confronto com o trabalho prescrito, resultando em uma prática diferente daquela prevista (Schwartz, 2006).

Com base nessas considerações, o estudo aqui apresentado buscou analisar o contexto de trabalho na percepção dos ACSs, identificando os possíveis fatores que contribuem para seu sofrimento/adoecimento. 


\section{Metodologia do estudo}

O estudo realizado foi do tipo transversal, descritivo, de abordagem quantitativo-qualitativa, e integra a pesquisa "Sofrimento no trabalho de agentes comunitários de saúde: um estudo nos municípios da $13^{\text {a }}$ Coordenadoria Regional de Saúde - RS", desenvolvida pelo Grupo de Estudos e Pesquisa em Saúde (GEPS), da Universidade de Santa Cruz do Sul (2017).

Integraram o estudo os ACSs de 34 equipes da Estratégia Saúde da Família (ESF) e cinco equipes da Estratégia de Agentes Comunitários de Saúde (EACSs) dos 13 municípios de abrangência da $13^{\text {a }}$ Coordenadoria Regional de Saúde (CRS), $28^{a}$ Região de Saúde do Rio Grande do Sul, localizados na região central do estado e com uma população total de 318.587 habitantes (Instituto Brasileiro de Geografia e Estatística, 2010). Um aspecto determinante e peculiar na região estudada foi a realidade de trabalho de ACSs em municípios constituídos, em sua maioria, por extensas áreas rurais, o que traduz um panorama focado na assistência a uma população com características não somente urbanas. A intenção do estudo foi traduzir essa realidade urbana e rural em suas características e especificidades, identificando os fatores sociais, econômicos, políticos e culturais, que podem ser determinantes para a organização do trabalho do ACS.

Utilizaram-se três instrumentos de coleta de dados: um questionário sociodemográfico (com nove questões), o formulário 'Inventário de trabalho e risco de adoecimento' (Itra), validado em estudos de Mendes e Ferreira (2007), e uma entrevista. Os dois primeiros instrumentos foram respondidos por 251 sujeitos, o que corresponde à população de ACSs dessa região. Em seguida, realizaram-se entrevistas do tipo semiestruturada com 15 agentes comunitários, em uma amostragem intencional, por município e tipo de estratégia. A entrevista, composta por 17 questões, teve a intenção de aprofundar os dados obtidos nos instrumentos quantitativos aplicados anteriormente.

O Itra é um inventário composto por quatro escalas que avaliam a inter-relação de trabalho e adoecimento, com o objetivo de levantar os fatores que podem interferir nesse processo, buscando traçar um perfil dos riscos de adoecimento provocado pela atividade profissional, dos efeitos que pode originar sobre o trabalhador e das dimensões da relação entre trabalho e trabalhador no que se refere ao contexto de trabalho, exigências, vivências e danos. Para o estudo, utilizou-se a primeira Escala de Avaliação do Contexto do Trabalho (EACT) e a terceira Escala de Indicadores de Prazer e Sofrimento no Trabalho (EIPST), com os fatores relacionados ao sofrimento, no trabalho denominados 'esgotamento profissional' e 'falta de reconhecimento'.

A EACT é uma escala do tipo Likert de cinto pontos. Contém 31 questões e é composta por três fatores (organização do trabalho, condições de trabalho e relações socioprofissionais). A EIPST é uma escala de frequência do tipo Likert de sete pontos. Tem 32 questões e avalia a ocorrência das vivências de prazer e sofrimento no trabalho nos últimos seis meses em quatro fatores: dois para ava- 
liar o prazer - 'realização profissional' e 'liberdade de expressão' - e dois para estimar o sofrimento - 'esgotamento profissional' e 'falta de reconhecimento'.

Os dados quantitativos foram organizados com o auxílio do software Statistical Package for Social Sciences 20.0 (SPSS). Na análise dos dados das escalas EACT e EIPST, obteve-se o escore fatorial com o cálculo da média entre os itens, considerando-se o ponto médio e o desvio padrão. Para a EACT, os resultados foram classificados em graves (escore acima de 3,7), moderados/críticos (escore de 2,3 a 3,69) e satisfatórios (escore abaixo de 2,29). Para a EIPST, os resultados foram classificados em avaliação mais negativa, grave (escores acima de 4,0); moderada, crítica (escores entre 3,9 e 2,1); menos negativa, satisfatória (escores abaixo de 2,0). Na análise da relação entre o perfil dos sujeitos e as escalas, utilizou-se estatística descritiva, com nível de significância de $\mathrm{p}<0,05$. Já os dados qualitativos foram analisados por meio da Análise de Conteúdo (Minayo, 2010), em uma categoria temática denominada 'fatores do trabalho contributivos para o adoecimento/sofrimento do trabalhador'.

A pesquisa foi aprovada pelo Comitê de Ética em Pesquisa da Universidade de Santa Cruz do Sul (Unisc), em 16 de junho de 2014, com o parecer de número 713.475 .

\section{Resultados da pesquisa}

Os 251 ACSs participantes da primeira etapa do estudo eram predominantemente do sexo feminino $(92,8 \%)$, com idades entre 31 e 40 anos $(37,5 \%)$, casados $(48,6 \%)$, com um a dois filhos (64,9\%). Quanto à escolaridade, 54,2\% tinham ensino médio completo e $13,2 \%$ estavam cursando o ensino superior ou já o haviam concluído. Desses ACSs, obteve-se a maior frequência de atuantes em $\operatorname{ESF}(59,8 \%)$ e, em menor expressão, em EACS $(40,2 \%)$, com predomínio de atuação em área urbana (50,2\%), seguindo-se área rural (43,8\%) e em ambas as áreas (5,25\%).

Na Escala de Avaliação do Contexto do Trabalho, o fator 'organização no trabalho' apresentou escore de média de 3,17, considerado como avaliação de moderada a crítica. O fator 'relações socioprofissionais', que alcançou um escore de 2,41, também apresentou uma avaliação de moderada a crítica, assim como o fator 'condições de trabalho', com escore de 2,60 (Tabela 1).

\section{Tabela 1}

\begin{tabular}{lcc}
\hline \multicolumn{2}{l}{ Escala de Avaliação do Contexto de Trabalho (EACT) dos agentes comunitários de saúde da 13a CRS - RS, 2014 } \\
\hline Fator & Média & Desvio padrão \\
\hline Organização no trabalho & 3,17 & 0,67 \\
Relações socioprofissionais & 2,41 & 0,84 \\
Condições de trabalho & 2,60 & 0,83 \\
\hline Total da dimensão & 2,80 & \\
\hline
\end{tabular}


Na Escala de Indicadores de Prazer e Sofrimento no Trabalho, o fator 'esgotamento profissional', com escore de 3,53, e o fator 'falta de reconhecimento', com escore de 2,51, foram igualmente avaliados como de moderado a crítico (Tabela 2).

\section{Tabela 2}

Fatores relacionados ao sofrimento da Escala de Indicadores de Prazer e Sofrimento no Trabalho dos agentes comunitários de saúde da 13a CRS - RS, 2014

\begin{tabular}{lcc}
\hline Fator & Média & Desvio padrão \\
\hline Esgotamento profissional & 3,53 & 1,53 \\
Falta de reconhecimento & 2,51 & 1,69 \\
\hline Total da dimensão & 3,11 & \\
\hline Fonte: Os autores. &
\end{tabular}

O fator 'organização no trabalho' apresentou associação estatisticamente significativa com as categorias 'idade' $(p=0,001)$, 'município' $(p=0,000)$, 'tipo de estratégia - ESF ou EACS' ( $p=0,001)$ e 'urbano ou rural' $(p=0,000)$. Em relação ao fator 'relação socioprofissional', observou-se que as categorias 'município' ( $\mathrm{p}=$ 0,000) e 'tipo de estratégia - ESF ou EACS' $(p=0,015)$ apresentaram significância, enquanto as demais não mostraram relação com este fator. Já o fator 'condições de trabalho' apresentou relação de significância com as categorias 'escolaridade' ( $p=0,013)$, 'município' ( $p=0,011)$ e 'urbano ou rural' $(p=0,028)$ (Tabela 3).

Tabela 3

\begin{tabular}{lccc}
\hline \multicolumn{3}{l}{ Associação de variáveis sociodemográficas e fatores da Escala de Avaliação do Contexto de Trabalho (EACT) } \\
\hline Variável/ Fator & $\begin{array}{c}\text { Organização do trabalho } \\
\left(\mathbf{p}^{*}\right)\end{array}$ & $\begin{array}{c}\text { Realização socioprofissional } \\
\left(\mathbf{p}^{*}\right)\end{array}$ & $\begin{array}{c}\text { Condições de trabalho } \\
\text { (p*) }\end{array}$ \\
\hline Idade & 0,001 & 0,083 & 0,348 \\
Sexo & 0,738 & 0,865 & 0,900 \\
Estado civil & 0,190 & 0,318 & 0,680 \\
Escolaridade & 0,504 & 0,518 & 0,013 \\
Filhos & 0,546 & 0,317 & 0,063 \\
Município & 0,000 & 0,000 & 0,011 \\
Tipo de estratégia & 0,001 & 0,015 & 0,635 \\
Área de atuação & 0,000 & 0,265 & 0,028 \\
\hline Fonte: Os autores. & & &
\end{tabular}

Nota: $\mathrm{p}^{*}$ - nível de significância estatística.

Para os fatores da escala EIPST referentes ao sofrimento, os resultados encontrados indicaram que o fator 'esgotamento profissional' apresentou relação de significância apenas com a categoria "município" ( $p=0,038)$, enquanto o fator 'falta de reconhecimento' apresentou associação estatisticamente significativa com as categorias 'idade' $(p=0,001)$, 'estado civil' $(p=0,042)$ e 'tipo de estratégia' $(p=0,001)$ (Tabela 4). 
Tabela 4

Associação de variáveis sociodemográficas e fatores relacionados ao sofrimento da Escala de Indicadores de Prazer e Sofrimento no Trabalho (EIPST)

\begin{tabular}{lcc}
\hline Variável/ Fator & $\begin{array}{c}\text { Esgotamento profissional } \\
\left(\mathbf{p}^{*}\right)\end{array}$ & $\begin{array}{c}\text { Falta de reconhecimento } \\
\left(\mathbf{p}^{*}\right)\end{array}$ \\
\hline Idade & & 0,171 \\
Sexo & & 0,465 \\
Estado civil & & 0,481 \\
Escolaridade & & 0,816 \\
Filhos & 0,038 & 0,057 \\
Município & & \\
Tipo de estratégia & & 0,813 \\
Área de atuação & & 0,277 \\
\hline
\end{tabular}

Fonte: Os autores.

Nota: $\mathrm{p}^{*}$ - nível de significância estatística.

Os 15 agentes que participaram das entrevistas na segunda etapa do estudo eram, em sua totalidade, do sexo feminino, com predomínio de idade entre 31 e 40 anos, casadas, com um a dois filhos e ensino médio completo. Desses ACSs, obteve-se a maior frequência de atuantes em ESF (1l sujeitos) e, em menor expressão, em EACS (quatro sujeitos). Quanto à área geográfica de atuação, seis sujeitos referiram atuar somente em área urbana, seis somente em área rural, enquanto três em áreas urbana e rural, simultaneamente.

Na categoria temática 'Fatores do trabalho contributivos para o adoecimento/sofrimento do trabalhador', os ACSs citaram fatores dificultadores, como a falta de tempo para desempenho das funções e a incapacidade em atender às demandas da comunidade:

(...) no meu trabalho, a correria do dia a dia, o sofrimento das pessoas fazem com que tu acabes ficando doente, né, tu vês situações que tu não podes resolver, tu podes correr, mas tu não... o resultado é que eu tomo antidepressivo (ACS 1).

Outro aspecto pontuado foi a falta de Equipamentos de Proteção Individual (EPIs) para desempenho de suas funções. A constante exposição ao sol, à chuva e a outros fatores locais oferecem riscos à saúde dos ACSs, que, quando não amparados pela ESF, acabam adquirindo materiais de proteção por conta própria:

Mordida de cachorro... gripe, porque a gente anda na chuva, né, o sol, a gente queima o rosto quando não tem protetor... Agora eles tão entregando, só que quanto tá em falta, quando a gente não tem em casa, né... (ACS 2).

Os ACSs citaram também a falta de resolutividade dos problemas do usuário como aspecto que dificulta o desempenho de suas atribuições. Essa descontinuidade das ações foi elucidada na seguinte fala: 
Um exemplo são as nossas visitas... A gente faz as visitas e os pacientes pedem, exigem tudo de nós, só que não depende de nós aquilo dar certo, entende. Aí a gente passa pra enfermeira, a enfermeira passa pra secretária e morre ali, entendeu? Aí a gente fica sem retorno, o paciente fica sem retorno e assim fica (ACS 3).

Como fatores relacionados ao campo da assistência ao usuário, foram apontados o forte envolvimento emocional com os usuários da ESF e o constante contato com situações de doença, que geram sentimentos de tristeza. Tal situação foi vista pelos ACSs como algo 'normal' e que faz parte do processo de trabalho:

(...) a gente se sensibiliza por causa das doenças... A gente mora na comunidade e conhece todo mundo, a gente cria aquele vínculo, a gente se apega (ACS 4).

Às vezes a gente fica um pouco assim, dependendo da situação que a gente vê, eu fico meio triste, bate aquela coisa de não poder fazer mais por eles, né, não tem o que fazer além de orientar... causa um pouquinho de sofrimento, mas é normal, né (ACS 5).

Além disso, a indisponibilidade de exames e materiais prejudica o desempenho de suas atividades:

Às vezes eles não conseguem o atendimento que realmente precisam na hora... As coisas são demoradas e a gente se preocupa também com isso... que eles não têm o atendimento que precisam no momento, no geral... exames e coisas que eles precisam, né... acho que falta um pouco disso (ACS 4).

Os ACSs citaram a distância percorrida durante as visitas como fator relacionado ao trabalho determinante para a ocorrência de adoecimento/sofrimento:

Às vezes, né... a gente sai, fica molhado, né... pega um resfriado, pega uma gripe... às vezes caminha bastante, aí as pernas doem de tanto caminhar... mas mesmo assim a gente tem o outro lado, né (EACS 1).

\section{Discussão dos resultados e relação com referenciais teóricos}

O estudo mostrou que os dados quantitativos e qualitativos se complementam, à medida que as entrevistas corroboraram os resultados apontados na análise do Itra em suas duas escalas de análise utilizadas (EACT e EIPST). Os dados revelaram as condições do trabalho em saúde, em que os ACSs alegaram o aumento de demanda e a incapacidade de atenderem a todas as solicitações da comunidade, assim como a não resolutividade dos problemas 
dos usuários e o constante contato com situações de doença como fatores que dificultam o desempenho de suas atribuições e contribuem para o seu sofrimento/adoecimento.

O trabalho em saúde se dá por meio de fluxos constantes entre indivíduos e do contato de trabalhadores com usuários, formando, desse modo, uma complexa rede de relações a partir da qual o cuidado ganha materialidade (Franco, 2006). A formação de conexões em diversas direções é uma característica presente no trabalho das equipes de saúde da família e base da atividade do ACS. Essa relação de vínculo estabelecida no ambiente de trabalho gera contato com situações de perda de privacidade e exposição, o que pode provocar sobrecarga e implicar sofrimento (Rosa, Bonfanti e Carvalho, 2012; Lopes et al., 2012).

Os ACSs pesquisados, além de apontarem para dicotomias entre o trabalho prescrito e o real (Schwartz, 2006), expuseram a singularidade desse trabalho no qual, em seu processo, são convocados os saberes elaborados pelo sujeito, que podem se distanciar e até confrontar com o trabalho prescrito.

Em sua grande maioria, os ACSs são mulheres, o que reforça a crescente feminização da força de trabalho na área da saúde e afirma o papel cuidador que a mulher sempre desempenhou na sociedade. Assim, as profissões ligadas ao cuidado, como a de ACS, ocupadas em sua maior parte por mulheres, são socialmente desvalorizadas, vistas muitas vezes como uma vocação natural, o que pode causar sofrimento ou adoecimento dessas trabalhadoras (Galavote et al., 2011; Costa et al., 2012).

Em relação à organização do trabalho, percebeu-se uma insatisfação com os ritmos e normas de trabalho impostos. Essa insatisfação remete a uma possível discrepância entre o trabalho prescrito, baseado na definição de tarefas que operacionalizam uma divisão do trabalho, fixa regras e dita objetivos, e o trabalho real, que traduz o trabalho realizado pelo sujeito em uma relação dialética entre o dizer e o fazer, o geral e o singular, o micro e o macro, o local e o global, o objetivo e o simbólico (Hennington, 2008). Tal discrepância permite uma reflexão sobre as numerosas barreiras enfrentadas pelos ACSs em seu cotidiano de trabalho, permeando uma relação contraditória que se reflete no fazer dos trabalhadores, que por diversas situações não conseguem realizar a ação da maneira prescrita ou desejada. É necessário normatizar, entretanto, as formas de organização do trabalho, que devem sempre deixar um espaço para serem retrabalhadas, em razão das renormatizações presentes. Assim, o trabalho real não se dá por meio da estrita aplicação e execução das normas; é, na verdade, o resultado das renormatizações (Schwartz, 2006).

Os ACSs citaram como fatores dificultantes a falta de tempo para o desempenho das funções e a incapacidade em atender às numerosas demandas da comunidade. Estudo realizado com ACSs de um município da região noroeste do Rio Grande do Sul (Costa et al., 2012) encontrou resultado semelhante, no qual 
os entrevistados relataram experimentar sobrecarga de trabalho em sua rotina profissional. Esses profissionais realizavam atividades que muitas vezes extrapolavam suas atribuições, tais como atividades administrativas e de recepção na ESF, evidenciando que havia, além da sobrecarga, um desvio de função no trabalho. Outros estudos encontraram resultado semelhante, o que reforça a ideia de que é atribuída a esses trabalhadores uma gama de atividades muito maior do que as propostas pelos programas ESF e EACS. Tal situação pode ocorrer em razão de o Ministério da Saúde permitir que o município adapte as tarefas do ACS de acordo com a realidade local, o que confere ao município liberdade para planejar as ações em saúde, ao mesmo tempo que abre espaço para situações de sobrecarga de atividades (Oliveira et al., 2010; Baralhas e Pereira, 2013). Esses fatores apontados pelo ACS como dificultantes relacionam-se à medida que a grande quantidade de tarefas prescritas inviabilize a execução de muitas das atividades. Em razão da necessidade de deslocamento até as residências e da realização de atividades educativas, além de ações que não são próprias do ACS, tem-se a necessidade de dividir o tempo disponível para a jornada de trabalho diária, que muitas vezes não é suficiente.

Estudo realizado em Minas Gerais identificou que, além das próprias atividades, os ACSs muitas vezes desempenham funções administrativas dentro das unidades de saúde, como agendamento de consultas e exames e conferência de materiais de estoque e médico-hospitalar, desviando-se de sua função e assumindo, muitas vezes, papel de auxiliar ou técnico em saúde (Costa et al., 2013). Frequentemente, o ACS não tem clareza de seu papel profissional, assumindo para si responsabilidades que seriam de toda a equipe de saúde, não se mostrando capaz de discernir sobre seus limites, tanto os relacionados à criação de vínculos quanto os pertinentes à atuação profissional. Esses limites imprecisos, associados à própria organização do trabalho, levam o ACS a um estado de tristeza, o que diminui sua potência de agir e engessa a sua criatividade e inventividade (Galavote et al., 2011).

No que diz respeito às relações socioprofissionais, os dados obtidos por meio do Itra foram complementados pelas entrevistas, quando os ACSs destacaram que o vínculo criado com a comunidade, muitas vezes, acabava gerando sofrimento. A ação do ACS está envolta de implicação pessoal e interpessoal, o que pode trazer conflitos e desgastes emocionais (Rosa, Bonfanti e Carvalho, 2012). Tal processo é potencializado pelo fato de o trabalho em saúde se dar sempre em um encontro, sendo, desse modo, centrado no trabalho vivo e trazendo em seu processo de produção toda a bagagem subjetiva própria do humano (Franco e Merhy, 2012).

Diante desse panorama, um fator relacionado ao trabalho capaz de provocar sofrimento está no fato de o ACS ser morador da comunidade onde trabalha, estabelecendo um forte vínculo com os usuários e promovendo uma mediação entre unidade de saúde e comunidade, o que origina uma intrínse- 
ca interação entre suas relações sociais e profissionais. O fato de exercer sua atividade de trabalho no mesmo espaço em que reside pode implicar maior demanda de tarefas e gerar sobrecarga quando o trabalhador apresenta dificuldade em se desligar do trabalho em seus momentos de folga (Vogt et al., 2012). A falta de entendimento da comunidade acerca do papel do ACS e a dificuldade em separar o profissional do vizinho reforçam a cobrança sobre o agente. Ao mesmo tempo, o ACS, como profissional, se reconhece como um elo que tem a responsabilidade de estabelecer o vínculo entre os profissionais da equipe e os usuários, o que não depende essencialmente do seu trabalho, pois não é possível que o agente crie vínculos pelos outros membros da equipe (Galavote et al., 2011).

Em relação às condições de trabalho, os ACSs precisam lidar com a indisponibilidade de materiais e insumos essenciais e com riscos que prejudicam a sua saúde e o desenvolvimento das tarefas prescritas. A região estudada tem a característica de comportar extensas áreas rurais, com estradas muitas vezes inóspitas e residências muito distantes ou isoladas. A constante exposição aos raios solares e à chuva durante as visitas domiciliares, os ataques de cães e o acesso dificultado aos núcleos rurais, geralmente muito distantes, expõem o ACS a riscos físicos significativos. Esses dados corroboram os achados de outros estudos em áreas rurais, demonstrando que as dificuldades encontradas durante as visitas domiciliares não são exclusividade dessa região (Baptistini e Figueiredo, 2014; Almeida, 2013). Por sua vez, uma pesquisa realizada em região urbana do Rio Grande do Sul também encontrou resultado semelhante e evidenciou que o trabalho seria menos desgastante para esses profissionais se o poder público disponibilizasse materiais como capas de chuva e protetor solar (Brand, Antunes e Fontana, 2010).

Percebe-se que a insuficiência ou a inadequação dos meios de trabalho podem dificultar a realização de atividades ou até mesmo impedi-las, reforçando a ideia de que as diretrizes institucionais devem vir acompanhadas de condições adequadas para serem efetivas (Bertoncini, Pires e Scherer, 2011). Assim, é de fundamental importância que os gestores dos serviços de saúde se comprometam com o fornecimento de equipamentos de trabalho necessários aos ACSs, conforme as necessidades dos serviços, buscando recursos e instrumentalização para esses trabalhadores, de modo a proporcionar um atendimento de qualidade para os usuários, bem como a promoção da saúde dos agentes comunitários (Vogt et al., 2012).

A convivência e o envolvimento emocional com os problemas sociais da comunidade também se apresentaram como uma situação geradora de esgotamento profissional apontada por ACSs em outra pesquisa realizada no Rio Grande do Sul, despertando sentimentos de frustração e impotência, sobretudo por se tratar de famílias com as quais eles têm laços afetivos (Lopes et al., 2012). O envolvimento afetivo pode fazer com que a dor do outro seja também 
a dor do ACS, proporcionando um envolvimento tão grande que o trabalhador envolvido acaba sofrendo ou adoecendo. Para os agentes, a maior motivação é o resultado de seu trabalho obtido a partir do cuidado com os usuários, apesar dos fracassos interpostos no encontro entre eles e a comunidade e pelo desenvolvimento da atividade em um território de conflitos, subjetividades, desejos e micropoderes (Galavote et al., 2013). No trabalho, qualquer sujeito ou grupo é um centro de vida, uma tentativa de apropriação do meio, e a vida no trabalho não é separada de sua ambição de vida global (Schwartz, 2011).

Apesar do enaltecimento de seu papel de mediadores, os ACSs destacaram a falta de reconhecimento e a baixa valorização profissional, já que muitas vezes os agravos à saúde da população transcendiam suas atribuições e possibilidades de resolutividade (Rosa, Bonfanti e Carvalho, 2012) - e o baixo reconhecimento afeta a produtividade desses trabalhadores (Santos e David, 2011). Os agentes comunitários são cobrados excessivamente pelos usuários em relação às suas questões de saúde e acabam gerenciando demandas que exigem um ritmo intenso de trabalho, grande responsabilidade e competência para a realização de tarefas cada vez mais complexas, situações que podem culminar em sofrimento ou adoecimento (Gomes et al., 2011). Ao mesmo tempo, a valorização social do trabalho de outros profissionais, em detrimento do ACS, produz nele experiências de fracasso e insatisfação, além de dificultar o acesso aos demais profissionais da equipe (Galavote et al., 2013). Essa expectativa de que seja um elo entre a comunidade e os serviços de saúde, aliada à falta de respostas às necessidades que lhe são impostas, o predispõe a sensações de impotência, frustração e consequente sofrimento/adoecimento (Souza e Freitas, 2011; Lancman et al., 2013).

Fato que merece destaque na análise dos dados encontrou-se na variável 'município', que apresentou relação significativa com os fatores 'organização do trabalho', 'relação socioprofissional', 'condições de trabalho' e 'esgotamento profissional'. Assim, pôde-se compreender a influência que o modo de condução da gestão municipal de saúde tinha sobre a organização do trabalho dos ACSs. Os limites impostos pela gestão na organização do trabalho incidem no agente comunitário, levando-o a um estado de tristeza e diminuição da sua potência de ação, o que engessa sua criatividade e sua inventividade (Galavote et al., 2013). Ao mesmo tempo, a variável 'tipo de estratégia' (ESF ou EACS), ao manifestar correlação com fatores da organização do trabalho, relação socioprofissional e falta de reconhecimento, demonstrou que o modelo de atenção adotado podia influenciar os processos de trabalho e seus impactos na vida dos ACSs. Evidenciou-se, assim, a importância do vínculo em relação aos usuários quanto à própria equipe, em que a possibilidade de ajudar o outro faz com que o ACS se reconheça como um agente de transformação no âmbito da ESF (Galavote et al., 2013).

Ainda a variável 'urbano ou rural' relacionou-se à organização e às condições de trabalho, evidenciando os impactos da localização do serviço de saúde, da estratégia e da moradia dos usuários atendidos no cotidiano dos ACSs. 
Os agentes que atuam no meio rural convivem com situações singulares. Um dos principais desafios é o acesso aos domicílios, geralmente distantes ou praticamente inacessíveis, o que exige do agente inovação e formas diferenciadas de produzir suas práticas e organizar seu cotidiano de trabalho (Baptistini e Figueiredo, 2014). Já os ACSs de áreas urbanas frequentemente atuam em locais de maior pobreza e vulnerabilidade social, o que os expõem com maior frequência a situações de violência (Souza e Freitas, 2011).

Dessa maneira, quando o contexto de trabalho limita ou não favorece o desenvolvimento das potencialidades do trabalhador, pode causar desgaste e insegurança. O ambiente de trabalho inadequado, a carência de materiais e o distanciamento entre o trabalho prescrito e o real, associados à falta de reconhecimento e dificuldades no relacionamento com a comunidade e com a equipe, produzem modos de organização que diminuem a autonomia dos ACSs, causando estresse e ansiedade nesses trabalhadores (Vogt et al., 2012). Os agentes comunitários, muitas vezes, não elaboram estratégias de enfrentamento para lidar com o sofrimento provocado pelo trabalho, o que os torna vulneráveis ao sofrimento constante ou adoecimento. Muitos dos trechos das entrevistas remeteram à sensação de tristeza, trazendo à tona um sentimento de incapacidade.

Os dados obtidos apontaram para a necessidade, na região estudada, da criação ou efetivação de espaços coletivos de planejamento do trabalho, por meio de uma gestão colegiada que permita a participação dos ACSs nos processos decisórios com a criação de espaços de escuta, encontros e construção de vínculos.

\section{Conclusão}

A realidade de trabalho estudada demonstrou uma lacuna importante entre o trabalho prescrito e o real, apontando a possibilidade de originar situações de sofrimento aos ACSs - somando-se, especificamente no estudo que originou este artigo, as influências da área de localização da unidade de saúde, a região de residência dos usuários, o tipo de estratégia e a gestão da saúde.

Com base na análise dos dados coletados, verificou-se que os agentes de saúde vivenciavam mais intensamente situações de sofrimento, daí surgirem sentimentos de insatisfação no trabalho relacionados ao não reconhecimento profissional das atividades desempenhadas. Além disso, os ritmos e normas impostos apresentaram-se como geradores de sobrecarga na jornada diária, oriundos das intensas demandas da comunidade, o que resultava em insatisfação profissional e desgaste físico e psicológico.

$\mathrm{O}$ vínculo com a comunidade, com seus conflitos e desgastes emocionais, a indisponibilidade de materiais e insumos essenciais e a existência de riscos que prejudicam sua saúde e o desenvolvimento das tarefas também foram 
referidos pelos agentes como fatores contributivos para seu sofrimento no trabalho. O não reconhecimento do trabalho pelos usuários, mediante ações de cuidado a eles, constitui-se como gerador de sofrimento e situações desgastantes no ambiente de trabalho.

O estudo aqui apresentado procurou contribuir para discussões e reflexões sobre as questões de saúde a partir do processo de trabalho dos ACSs, ao se considerar que a identificação de situações geradoras de sofrimento/adoecimento propicia o desencadeamento de ponderações sobre a forma como esse trabalho vem sendo organizado. Ressalta-se, portanto, a importância - por parte de instituições, gestores e dos próprios trabalhadores - de um olhar atento aos fatores presentes no ambiente de trabalho que representem riscos de adoecimento do ACS. Entre essas estratégias, podem ser sugeridas medidas centradas em mudanças na organização do processo de trabalho, com o objetivo de promover o bem-estar e evitar o adoecimento, de modo a prover ao ACS mais autonomia para pensar, refletir e criar, de maneira que tenha liberdade necessária para o protagonismo e a cogestão de seu trabalho.

\section{Colaboradores}

Suzane Beatriz Frantz Krug foi a coordenadora do projeto e pesquisadora, contribuindo na redação e revisão crítica do artigo. Camila Dubow participou da redação do artigo. Amanda Corrêa dos Santos contribuiu na análise dos dados e redação do artigo. Bruno Dittberner Dutra participou da análise estatística e da metodologia. Leni Dias Weigelt e Luciane Maria Schmidt Alves, além da redação, participaram da revisão do artigo. 
Resumen El estudio tuvo como objetivo analizar cómo el agente comunitario de salud evalúa su contexto de trabajo y los posibles factores que contribuyen para su sufrimiento/padecimiento. Se trató de un estudio transversal, descriptivo, de enfoque cuantitativo y cualitativo, con agentes de salud de 13 municipios de la región central del estado de Río Grande do Sul, Brasil, en el año 2014. Para la recolección de datos se utilizó un cuestionario sociodemográfico, el "Inventario de trabajo y riesgo de padecimiento" y entrevista. Los datos se estudiaron mediante el análisis de contenido. Las situaciones de sufrimiento se relacionaron con la falta de reconocimiento profesional, ritmos excesivos, sobrecarga de trabajo, conflictos con la comunidad, falta de resolutividad de las acciones, no disponibilidad de materiales e insumos aunados a la ubicación geográfica de la unidad de salud y de las residencias de los usuarios, tipo de estrategia y gestión de la salud. Se concluyó que el contexto de trabajo del agente de salud puede resultar en sufrimiento/padecimiento de estos trabajadores.

Palabras clave agentes comunitarios de salud; trabajo; enfermedad.

\section{Notas}

${ }^{1}$ Universidade de Santa Cruz do Sul, Departamento de Enfermagem e Odontologia, Programa de Pós-Graduação em Promoção da Saúde. Santa Cruz do Sul, Rio Grande do Sul, Brasil.

$<$ skrug@unisc.br>

Correspondência: Universidade de Santa Cruz do Sul, Programa de Pós-Graduação em Promoção da Saúde, Av. Independência, 2.293, CEP 96816-501, Santa Cruz do Sul, Rio Grande do Sul, Brasil.

${ }^{2}$ Universidade de Santa Cruz do Sul, Programa de Pós-Graduação em Promoção da Saúde, Santa Cruz do Sul, Rio Grande do Sul, Brasil.

<camiladubow@yahoo.com.br>

${ }^{3}$ Universidade de Santa Cruz do Sul, Departamento de Enfermagem e Odontologia, Santa Cruz do Sul, Rio Grande do Sul, Brasil.

$<$ acorrea@mx2.unisc.br>

${ }^{4}$ Universidade de Santa Cruz do Sul, Departamento de Fisioterapia, Santa Cruz do Sul, Rio Grande do Sul, Brasil.

<brunodittberner@hotmail.com>

${ }^{5}$ Universidade de Santa Cruz do Sul, Departamento de Enfermagem e Odontologia, Santa Cruz do Sul, Rio Grande do Sul, Brasil.

$<$ lenid@unisc.br>

${ }^{6}$ Universidade de Santa Cruz do Sul, Departamento de Enfermagem e Odontologia, Santa Cruz do Sul, Rio Grande do Sul, Brasil.

$<$ lucianealves@unisc.br> 


\section{Referências}

ALMEIDA, Mirian C. S. Acidentes de trabalho ocorridos com agentes comunitários de saúde no município de Caraguatatuba-SP. 2013. 122f. Dissertação (Mestrado em Enfermagem) - Universidade de Guarulhos, Guarulhos, 2013.

BAPTISTINI, Renan A.; FIGUEIREDO, Tulio A. M. Agente comunitário de saúde: desafios do trabalho na zona rural. Ambiente \& Sociedade [online], São Paulo, v. 17, n. 2, p. 53-70, 2014. Disponível em: <http:// www.scielo.br/scielo.php?script $=$ sci_arttext $\&$ pid $=$ S1414-753X2014000200005 > . Acesso em: $11 \mathrm{dez} .2015$.

BARALHAS, Marilisa; PEREIRA, Maria A. O. Prática diária dos agentes comunitários de saúde: dificuldades e limitações da assistência. Revisa Brasileira de Enfermagem, Brasília, v. 66, n. 3, p. 358-365, 2013. Disponível em: <http://www.scielo.br/scielo.php?script=sci_ arttext\&pid=S0034-71672013000300009>. Acesso em: 20 dez. 2015.

BERTONCINI, Judite H; PIRES, Denise E. P.; SCHERER, Magda D. A. Condições de trabalho e renormalizações nas atividades das enfermeiras na saúde da família. Trabalho, Educação e Saúde, Rio de Janeiro, v. 9, supl. 1, p. 157-173, 2011. Disponível em: <http:// www.scielo.br/scielo.php?script=sci_arttext\&pid=S1981-77462011000400008>. Acesso em: 31 jul. 2016.

BRAND, Cátia I.; ANTUNES, Raquel M.; FONTANA, Rosane T. Satisfações e insatisfações no trabalho do agente comunitário de saúde. Cogitare Enfermagem, Curitiba, v. 15, n. 1, p. 40-47, 2010. Disponível em: <http://revistas. ufpr.br/cogitare/article/viewFile/17143/11285>. Acesso em: 12 dez. 2015.

BRASIL. Ministério da Saúde. Programa agentes comunitários de saúde (Pacs). Brasília: Ministério da Saúde, 2001. Disponível em: <http:// bvsms.saude.gov.br/bvs/publicacoes/pacs01. pdf>. Acesso em: 5 dez. 2015.
BRASIL. Lei n. 10.507, de 10 de julho de 2002. Dispõe sobre a criação da profissão de agente comunitário de saúde e dá outras providências. Diário Oficial da República Federativa do Brasil, Brasília, 11 jul. 2002. Disponível em: <http://legis.senado.gov.br/legislacao/ ListaPublicacoes.action? $\mathrm{id}=235057>$. Acesso em: 15 out. 2015.

BRASIL. Ministério da Saúde. Política Nacional de Atenção Básica. Brasília: Ministério da Saúde, 2012. Disponível em: <http://189.28.128.100/ dab/docs/publicacoes/geral/pnab.pdf $>$. Acesso em: 5 dez. 2015.

COSTA, Marta C. et al. Processo de trabalho dos agentes comunitários de saúde: possibilidades e limites. Revista Gaúcha de Enfermagem [online], Porto Alegre, v. 33, n. 3, p. 134-140, 2012. Disponível em: <http:// www.scielo.br/scielo.php?script=sci_arttext\&pid=S1983-14472012000300018> . Acesso em: 4 dez. 2015.

COSTA, Simone M. et al. Agente comunitário de saúde: elemento nuclear das ações em saúde. Ciência \& Saúde Coletiva, Rio de Janeiro, v. 7, n. 18, p. 2.147-2.156, 2013. Disponível em: $<$ http://www.scielo.br/scielo.php?script=sci arttext\&pid $=$ S1413-81232013000700030 $>$. Acesso em: 11 dez. 2015.

FRANCO, Túlio B. As redes na micropolítica do processo de trabalho em saúde. In: PINHEIRO, Roseni; MATTOS, Ruben A. (orgs.). Gestão em redes: práticas de avaliação, formação e participação na saúde. Rio de Janeiro: Cepesc-IMS/ Uerj-Abrasco, 2006. p. 459-474. Disponível em: <https://www.cepesc.org.br/wp-content/ uploads/2013/08/gestao-em-redes-final.pdf $>$. Acesso em: 18 out. 2016.

FRANCO, Tulio B.; MERHY, Emerson E. Cartografias do trabalho e cuidado em saúde. Tempus: Actas de Saúde Coletiva, Brasília, v. 6, n. 2, p. 151-163, 2012. Disponível em: <http://www. tempusactas.unb.br/index.php/tempus/article/ view/1120/1034>. Acesso em: 31 jul. 2016. 
GALAVOTE, Heletícia S. et al. Desvendando os processos de trabalho do agente comunitário de saúde nos cenários revelados na Estratégia Saúde da Família no município de Vitória (ES, Brasil). Ciência \& Saúde Coletiva, Rio de Janeiro, v. 16, n. 1, p. 231-240, 2011. Disponível em: $<$ http://www.scielo.br/scielo.php?script=sci_ arttext\&pid $=$ S1413-81232011000100026 $>$. Acesso em: 7 dez. 2015.

GALAVOTE, Heletícia S. et al. Alegrias e tristezas no cotidiano de trabalho do agente comunitário de saúde: cenários de paixões e afetamentos. Interface: Comunicação, Saúde e Educação, Botucatu, v. 17, n. 46, p. 575-586, 2013. Disponível em: $<$ http://www.scielo.br/pdf/icse/2013nahead/ aop2213.pdf>. Acesso em: 14 dez. 2015.

GOMES, André L. et al. O elo entre o processo e a organização do trabalho e a saúde mental do agente comunitário de saúde na Estratégia Saúde da Família no município de João Pessoa - Paraíba - Brasil. Revista Brasileira de Ciências da Saúde, João Pessoa, v. 15, n. 3, p. 265-276, 2011. Disponível em: <http://bases.bireme.br/ cgi-bin/wxislind.exe/iah/online/?IsisScript=iah/ iah. $x i s \& s r c=$ google $\&$ base $=$ LILACS\&lang $=$ p\&nextAction $=\operatorname{lnk} \&$ exprSearch $=613376 \&$ indexSearch=ID > . Acesso em: $12 \mathrm{dez} .2015$.

HENNINGTON, Élida A. Gestão dos processos de trabalho e humanização em saúde: reflexões a partir da ergologia. Revista de Saúde Pública, São Paulo, v. 42, n. 3, p. 555-561, 2008. Disponível em: <http://www.scielo.br/pdf/rsp/ v42n3/6707.pdf>. Acesso em: 30 jul. 2016.

\section{INSTITUTO BRASILEIRO DE GEOGRAFIA E} ESTATÍSTICA. Censo demográfico 2010: Banco de dados agregados do IBGE. 2011. Disponível em: <https://cidades.ibge.gov.br/>. Acesso em: 25 maio 2016.

JUSTO, Célia M. P.; GOMES, Mara H. A.; SILVEIRA, Cássio. Limites e imposições dos instrumentos de controle do trabalho de agentes comunitários de saúde da Estratégia Saúde da Família. Saúde e Sociedade, São Paulo, v. 24, n. 2, p. 594-606, 2015. Disponível em: <http://www.revistas.usp.br/sausoc/article/ view/104830>. Acesso em: 28 out. 2015.
LANCMAN, Selma et al. Estudo do trabalho e do trabalhar no Núcleo de Apoio à Saúde da Família. Revista de Saúde Pública, São Paulo, v. 47, n. 5, p. 968-975, 2013. Disponível em: <http://www.revistas.usp.br/rsp/article/ view/76708>. Acesso em: 13 dez. 2015.

LOPES, Denise M. Q. et al. Agentes comunitários de saúde e as vivências de prazer: sofrimento no trabalho - estudo qualitativo. Revista da Escola de Enfermagem da USP [online], São Paulo, v. 46, n. 3, p. 633-640, 2012. Disponível em: <http://www.scielo.br/scielo.php?scrip$\mathrm{t}=$ sci_arttext\&pid=S0080-62342012000300015>. Acesso em: 7 dez. 2015.

MENEGUSSI, Juliana M.; OGATA, Márcia N.; ROSALINI, Maria H. P. O agente comunitário de saúde como morador, trabalhador e usuário em São Carlos, São Paulo. Trabalho, Educação e Saúde, Rio de Janeiro, v. 12, n. 1, p. 87-106, 2014. Disponível em: <http://www.scielo.br/scielo. php? pid $=$ S1981 $=77462014000100006-\&$ script sci_abstract\&tlng =pt $>$. Acesso em: 3 dez. 2015.

MENDES, Ana Magnólia B.; FERREIRA, Mário C. Inventário sobre Trabalho e Riscos de Adoecimento - Itra: instrumento auxiliar de diagnóstico de indicadores críticos no trabalho. In: MENDES, A. M. B. (org.). Psicodinâmica do trabalho: teoria, método e pesquisa. São Paulo: Casa do Psicólogo, 2007. p. 111-126.

MINAYO, Maria Cecília. O desafio do conhecimento: pesquisa qualitativa em saúde. São Paulo: Hucitec; Rio de Janeiro: Abrasco. 2010.

OLIVEIRA, Arleusson R. et al. Satisfação e limitação no cotidiano de trabalho do agente comunitário de saúde. Revista Eletrônica de Enfermagem, Goiânia, n. 12, v. 1, p. 28-36, 2010. Disponível em: <http://www.revistas. ufg.br/index.php/fen/article/view/9511/6580>. Acesso em: 28 out. 2015

PINHEIRO, Ricardo L.; GUANAES-LORENZI Carla. Funções do agente comunitário de saúde no trabalho com redes sociais. Estudos de Psicologia [online], Natal, v. 19, n. 1, p. 48-57, 2014. Disponível em: <http://www.scielo.br/scielo. php? pid $=$ S1413=294-2014000100007X\&script sci_abstract\&tlng =pt $>$. Acesso em: 7 dez. 2015. 
ROSA, Alcindo J.; BONFANTI, Ana L.; CARVALHO, Cintia S. O sofrimento psíquico de agentes comunitários de saúde e suas relações com o trabalho. Saúde e Sociedade, São Paulo, v. 21, n. 1, p. 141-152, 2012. Disponível em: $<$ http://www.scielo.br/pdf/sausoc/v2lnl/14. pdf $>$. Acesso em: $11 \mathrm{dez} .2015$.

SANTOS, Ítalo E. R.; VARGAS, Marlizete M.; REIS, Francisco P. Estressores laborais em agentes comunitários de saúde. Revista Psicologia, Organizações e Trabalho, Brasília, v. 14, n. 3, p. 324-335, 2014. Disponível em: $<$ http://pepsic.bvsalud.org/pdf/rpot/v14n3/ v14n3a08.pdf $>$. Acesso em: 10 ago. 2015.

SANTOS, Luiz F. B.; DAVID, Helena M. S. L. Percepções do estresse no trabalho pelos agentes comunitários de saúde. Revista Enfermagem Uerj, Rio de Janeiro, v. 19, n. 1, p. 52-57, 2011. Disponível em: <http://www. facenf.uerj.br/v19nl/v19nla09.pdf $>$. Acesso em: 11 dez. 2015.

SCHWARTZ, Yves. Entrevista: Yves Schwartz. Trabalho, Educação e Saúde, Rio de Janeiro, v. 4, n. 2, p. 457-466, 2006. Disponível em: $<$ http://www.scielo.br/pdf/tes/v4n2/15.pdf $>$. Acesso em: 3 ago. 2016.

SCHWARTZ, Yves. Conceituando o trabalho, o visível e o invisível. Trabalho, Educação e Saúde, Rio de Janeiro, v. 9, supl. 1, p. 19-45, 2011. Disponível em: <http://www. scielo.br/scielo.php?script=sci_arttext\&pi$\mathrm{d}=$ S1981-77462011000400002 > . Acesso em: 3 ago. 2016.

SOUZA, Lázaro J. R.; FREITAS, Maria C. O agente comunitário de saúde: violência e sofrimento no trabalho a céu aberto. Revista Baiana de Saúde Pública, Salvador, v. 35, n. 1, p. 96-109, 2011. Disponível em: <http:// bases.bireme.br/cgi-bin/wxislind.exe/iah/ online/?IsisScript $=$ iah/iah. $x$ is $\&$ src $=$ google $\& b a-$ $\mathrm{se}=$ LILACS\&lang $=\mathrm{p} \&$ nextAction $=\operatorname{lnk} \&$ expr Search $=593632 \&$ indexSearch $=$ ID $>$. Acesso em: 12 dez. 2015.

UNIVERSIDADE DE SANTA CRUZ DO SUL. Sofrimento no trabalho de agentes comunitários de saúde: um estudo nos municipios da $13^{a}$ Coordenadoria Regional de Saúde - RS . 2015. Disponível em: <http://www.unisc. $\mathrm{br} / \mathrm{pt} /$ pesquisa/a-pesquisa/consulta-a-projetos-de-pesquisa >. Acesso em: 28 jun.2017.

VOGT, Maria S. et al. Cargas físicas e psíquicas no trabalho de agentes comunitários de saúde. Cogitare Enfermagem, Curitiba, v. 17, n. 2, p. 297-303, 2012. Disponível em: <http://revistas. ufpr.br/cogitare/article/view/23559/184880>. Acesso em: 11 dez. 2015.

Recebido em 07/07/2016

Aprovado em 19/10/2016 
